Review Article

\title{
Pharmacological Effects of Centella asiatica on Skin Diseases: Evidence and Possible Mechanisms
}

\author{
Kyoung Sik Park \\ Division of BT Convergence, College of Engineering, Cheongju University, Cheongju, Chungbuk, Republic of Korea \\ Correspondence should be addressed to Kyoung Sik Park; pks0322@hanmail.net
}

Received 21 September 2021; Revised 27 October 2021; Accepted 11 November 2021; Published 20 November 2021

Academic Editor: ngelo Lu s

Copyright (C) 2021 Kyoung Sik Park. This is an open access article distributed under the Creative Commons Attribution License, which permits unrestricted use, distribution, and reproduction in any medium, provided the original work is properly cited.

\begin{abstract}
The medicinal herb Centella asiatica (L.) Urban known as gotu kola has been reported to exhibit a wide range of pharmacological activities. In particular, a significant body of scientific research exists on the therapeutic properties of preparations of $C$. asiatica or its triterpenes in the treatment of skin diseases. The present study is aimed to provide a comprehensive overview of the beneficial effects of C. asiatica on skin diseases. Peer-reviewed articles on the potent dermatological effects of C. asiatica were acquired from PubMed, Web of Science, Scopus, ScienceDirect, and SciFinder. This review provides an understanding of pharmacological studies which confirm the potent dermatological effects and underlying molecular mechanisms of C. asiatica. This medicinal plant and its triterpenes include asiaticoside, madecassoside, and their aglycones, asiatic acid and madecassic acid. These compounds exert therapeutic effects on dermatological diseases such as acne, burns, atopic dermatitis, and wounds via NF- $\kappa \mathrm{B}$, TGF- $\beta /$ Smad, MAPK, Wnt/ $\beta$-catenin, and STAT signaling in in vitro and in vivo studies. However, additional rigorously controlled long-term clinical trials will be necessary to confirm the full potential of $C$. asiatica as a therapeutic agent.
\end{abstract}

\section{Introduction}

Centella asiatica (L.) Urban is a perennial plant that grows in swampy areas of tropical and subtropical regions of India, Southeast Asia, and Malaysia, as well as some temperate regions of China, Korea, Japan, and Taiwan [1]. The herb, also known as gotu kola or Indian pennywort, is a valued medicinal plant widely used in the Orient to treat infectious skin diseases and accelerate the healing of skin ulcers and wounds. In addition, internal preparations have been applied to treat dysentery, gastric ulcers, and syphilitic lesions [2].

Secondary metabolites found in the aerial parts of C. asiatica are classified into pentacyclic triterpenoids, sesquiterpenes, plant sterols, and saponins [3]. The herb is rich in pentacyclic triterpenoids $\left(\mathrm{C}_{30}\right)$, of which the most abundant bioactive substances include asiaticoside, madecassoside, and their aglycones, asiatic acid and madecassic acid [1]. Essential oils from plants contain high levels of sesquiterpenes $\left(C_{15}\right)$ and monoterpenes $\left(C_{10}\right)$, including $\alpha$-humulene, $\beta$-caryophyllene, myrcene, bicyclogermacrene, and germacrene-D [4]. Other constituents found in the aerial part of $C$. asiatica have been characterized as chlorogenic acids, isomeric dicaffeolyl esters, and flavonoids such as catechin, epicatechin, kaempferol, and quercetin [5].

A growing body of research suggests therapeutic potentials of $C$. asiatica in treatment of neurological, endocrine, cardiovascular, digestive, respiratory, and dermatological diseases [6]. Investigations have reported that $C$. asiatica enhances the functions of the nervous system; C. asiatica and its triterpenes have a positive effect in relieving symptoms of Parkinson's disease [7] and Alzheimer's disease [8]. In addition, $C$. asiatica extracts have been reported to be effective in the treatment of endocrine diseases such as type 2 diabetes [9-11] and obesity [12]. Asiaticoside and asiatic acid, the active compounds of C. asiatica, have positive effects on cardiovascular diseases including hypertension $[13,14]$ and atherosclerosis $[15,16]$. C. asiatica extract and its triterpenes exert protective effects against liver injury [17-20] and gastrointestinal tract damage $[21,22]$. Asiaticoside and asiatic acid also have therapeutic effects on respiratory disorders such as pulmonary fibrosis 
[23], chronic obstructive pulmonary disease [24], and acute lung injury [25]. In particular, several in vitro and in vivo studies suggest that $C$. asiatica extracts and their triterpenes hold great promise as natural remedies that mitigate acne, burns, atopic dermatitis, and wounds $[6,26]$.

The aim of the current study was not only to review the pharmacological effects of $C$. asiatica on skin diseases but also to elucidate the possible underlying mechanisms of dermatological activity. Although a review paper had discussed the benefits of C. asiatica in dermatology a decade ago [26], it is necessary to include reports published after that time. Database searches using PubMed, Web of Science, Scopus, ScienceDirect, and SciFinder were performed until August 2021 to include up-todate documented information in the present review. For data mining, the following descriptors were applied in the databases mentioned above: C. asiatica, triterpene, asiaticoside, madecassoside, asiatic acid, madecassic acid, therapeutic effect, treatment, prevention, skin disease, acne, burns, atopic dermatitis, and wounds. In almost all cases, original articles were obtained and the relevant data were extracted.

\section{Pharmacological Effects of Centella asiatica on Skin Diseases}

The therapeutic effect of $C$. asiatica on skin diseases has been reported to treat or relieve acne (Table 1), burns (Table 2), atopic dermatitis (Table 3 ), and wounds (Table 4) $[6,26]$.

2.1. Acne. Acne is a common chronic inflammatory skin disease that affects the pilosebaceous units of the skin [27]. The four main pathological factors involved in the development of acne include increased sebum production, irregular follicular desquamation, Propionibacterium acnes proliferation, and inflammation [28]. In particular, $P$. acnes proliferation may trigger the release of chemostatic factors such as neutrophils, which may cause follicular damage and rupture and leakage of bacteria, fatty acids, and lipids into the surrounding dermis. This process results in the formation of inflammatory lesions [29].

The methanol extract of $C$. asiatica was assayed for antibacterial activity using a disk diffusion assay [30]. The inhibition zones for the disks with $60 \mu \mathrm{L}$ of $15 \mathrm{mg} / \mathrm{mL}$ C. asiatica extract were $<15 \mathrm{~mm}$ against $P$. acnes, indicating that the $C$. asiatica extract showed little antibacterial activity against $P$. acnes. Although the herbal mixture containing the $C$. asiatica extract exhibited high antimicrobial activity against $P$. acnes with $31.25 \mu \mathrm{g} / \mathrm{mL}$ of minimum inhibitory concentration (MIC), it did not support the antibacterial activity against $P$. acnes [31]. Purified madecassoside is a major pentacyclic triterpene saponin from C. asiatica. In contrast to the low antimicrobial activity of $C$. asiatica extract against $P$. acnes, the purified madecassoside significantly inhibited the production of proinflammatory cytokine IL-1 $\beta$, TLR2 expression, and nuclear translocation of NF$\kappa \mathrm{B}$ in $P$. acnes-stimulated THP-1 human monocytic cells [32].

2.2. Burns. Burns result in the development of a dysregulated inflammatory and stress host response characterized by elevated levels of cytokines, chemokines, and acute phase proteins [33]. Following the inflammatory response, activation of keratinocytes and fibroblasts via various cytokines and growth factors helps restore vascular perfusion and further promotes wound healing. The next phase of healing involves wound remodeling, in which collagen and elastin are deposited and continuously transform fibroblasts into myofibroblasts. Over time, a delicate balance between contraction of myofibroblasts and reepithelialization determines the quality and pliability of the repaired wounds and determines the extent of scar formation, which is characterized by fibrous malposition of collagen fibers [34].

One study confirmed the burn wound-healing properties of asiaticoside and madecassoside [35]. Topical treatment with asiaticoside and madecassoside not only induced collagen synthesis, proliferation, and cell growth but also stimulated burn wound healing in male ICR mice. Cytol Centella ${ }^{\circledR}$ is a commercial cream formulated with a titrated extract of C. asiatica. Topical application of Cytol Centella ${ }^{\circledR}$ significantly stimulated burn wound contraction by facilitating collagen synthesis in male Wistar rats [36].

Topical application with Centiderm ointment made from C. asiatica ethanol extract significantly improved the objective (pliability, vascularity, pigmentation, height, and visual acuity scores) and subjective (dryness, itching, and irritation) signs in patients with second-degree burn wounds on their limbs [37]. In addition, the means of reepithelialization and complete healing were significantly better in the Centiderm group than in the control group. Polyester coated with herbal extract ( $5 \%$ C. asiatica extract and $2.5 \%$ Aloe vera extract) dressings on the burn wound area facilitated burn wound healing, reduced the sizes of burn wounds with higher \% epithelialization, and decreased pain scores in another clinical trial [38].

2.3. Atopic Dermatitis. Atopic dermatitis (AD) is the most common inflammatory skin disorder that induces intense itching, edema, erythema, thickening, severe pruritus, and eczematous skin lesions. The pathogenesis of AD is multifactorial, involving immunologic processes including type 1 IgE dysfunction, defects in cell-mediated immune responses, and changes related to barrier dysfunction [39].

The therapeutic effect of a test material on AD is usually evaluated using phthalic anhydride (PA)-induced AD animal models. Titrated extract of $C$. asiatica (TECA) treatment attenuated the development of PA-induced AD by inhibiting the expression of iNOS and COX-2, NF- $\kappa$ B activity, and the release of TNF- $\alpha$, IL- $1 \beta$, IL- 6 , and IgE [40]. Another similar report supports the therapeutic effect of $C$. asiatica on $\mathrm{AD}$ in PA-induced AD animal models. Topical treatment with C. asiatica phytosome inhibited the expression of iNOS and COX-2, the activity of NF- $\kappa$ B, and the release of TNF- $\alpha$, IL$1 \beta$, and IgE, leading to the suppression of inflammatory cell infiltration [41]. Furthermore, TECA mixed with astaxanthin augmented the inhibitory effect of TECA on PAinduced morphological changes in skin and ear thickness [42]. Interestingly, both topical and oral administration of C. asiatica ethanol extract decreased mast cell infiltration in the ear tissue and reduced the expression of various 
TABle 1: Pharmaceutical effect of C. asiatica on acne.

\begin{tabular}{lcccc}
\hline Material tested & Cell line/assay system & $\begin{array}{c}\text { In vitro } \\
\text { Maximum } \\
\text { concentration }\end{array}$ & Effect & Low antibacterial activity against \\
\hline $\begin{array}{l}\text { C. asiatica methanol extract } \\
\begin{array}{l}\text { Herbal mixture containing } \\
\text { C. asiatica extract }\end{array}\end{array}$ & Disk diffusion assay & $15 \mathrm{mg} / \mathrm{ml}$ & [30] \\
$\begin{array}{l}\text { Purified madecassoside } \\
\text { P. acnes-stimulated THP-1 } \\
\text { human monocytic cell line }\end{array}$ & $500 \mu \mathrm{M}$ & $\begin{array}{c}\text { TLR2 expression and nuclear } \\
\text { translocation of NF- } \kappa \mathrm{B} \downarrow\end{array} \quad[31]$ \\
\hline
\end{tabular}

ND: not determined; MIC: minimum inhibitory concentration.

TABLE 2: Pharmaceutical effect of C. asiatica on burns.

\begin{tabular}{|c|c|c|c|c|}
\hline \multicolumn{5}{|c|}{ In vivo } \\
\hline Material tested & Animal model & Dose, duration & Effect & Reference \\
\hline $\begin{array}{l}\text { Each of asiaticoside and } \\
\text { madecassoside }\end{array}$ & Male SD rats & $\begin{array}{c}0.5 \mu \mathrm{l} \text { on the area of burning } \\
\text { wounds, } 14 \mathrm{~d}\end{array}$ & $\begin{array}{l}\text { Collagen synthesis and cell } \\
\text { proliferation } \uparrow \text {; burn wounds } \downarrow\end{array}$ & {$[35]$} \\
\hline $\begin{array}{l}\text { Cytol Centella }{ }^{\circledR} \text { (titrated } \\
\text { extract of C. asiatica) }\end{array}$ & Male Wistar rats & $\begin{array}{c}0.13 \mathrm{mg} / \mathrm{mm}^{2} \text { on the area of } \\
\text { burning wounds, } 33 \mathrm{~d}\end{array}$ & $\begin{array}{c}\text { Burn wound contraction } \uparrow \text {; } \\
\text { collagen synthesis } \uparrow\end{array}$ & {$[36]$} \\
\hline \multicolumn{5}{|c|}{ Clinical trial } \\
\hline Material tested & $\begin{array}{l}\text { Study design/volunteer } \\
(n)\end{array}$ & Dose, duration & Effect & Reference \\
\hline $\begin{array}{l}\text { Centiderm ointment } \\
\text { containing C. asiatica ethanol } \\
\text { extract }\end{array}$ & $\begin{array}{l}\mathrm{RCT}, \mathrm{DB} / \text { patients with } \\
\text { second-degree burn } \\
\text { wounds on their limbs } \\
\quad(n=60)\end{array}$ & $\begin{array}{l}\text { Appropriate amounts on the } \\
\text { area of burning wounds, } 25 \mathrm{~d}\end{array}$ & $\begin{array}{c}\text { Objective and subjective signs } \uparrow \text {; } \\
\text { mean of reepithelialization and } \\
\text { healing completion } \uparrow\end{array}$ & [37] \\
\hline $\begin{array}{l}\text { Polyester coated with herbal } \\
\text { extracts ( } 5 \% \text { C. asiatica extract } \\
\text { and } 2.5 \% \text { Aloe vera extract) }\end{array}$ & $\begin{array}{l}\text { RCT, DB/patients with } \\
\text { second-degree burn } \\
\text { wounds }(n=35)\end{array}$ & $\begin{array}{l}\text { Covering the area of burning } \\
\text { wounds with the dressings } \\
\text { with change every } 3 \text { days, } 21 \mathrm{~d}\end{array}$ & $\begin{array}{l}\text { Burn wound healing } \uparrow \text {; sizes of } \\
\text { burn wounds with higher \% } \\
\text { epithelialization } \downarrow \text {; pain scores } \downarrow\end{array}$ & {$[38]$} \\
\hline
\end{tabular}

Table 3: Pharmaceutical effect of C. asiatica on atopic dermatitis.

\begin{tabular}{|c|c|c|c|c|}
\hline \multicolumn{5}{|c|}{ In vivo } \\
\hline Material tested & Animal model & Dose, duration & Effect & Reference \\
\hline $\begin{array}{l}\text { Titrated extract of } \\
\text { C. asiatica (TECA) }\end{array}$ & $\begin{array}{l}\text { Phthalic anhydride-induced } \\
\text { AD model }\end{array}$ & $\begin{array}{c}40 \text { or } 80 \mu \mathrm{g} / \mathrm{cm}^{2}, 3 \\
\text { times a week for } \\
4 \mathrm{wk}\end{array}$ & $\begin{array}{l}\text { Development of AD } \downarrow \text {; hyperkeratosis and } \\
\text { inflammatory cell infiltration } \downarrow\end{array}$ & {$[40]$} \\
\hline C. asiatica phytosome & $\begin{array}{l}\text { Phthalic anhydride-induced } \\
\text { AD model }\end{array}$ & $\begin{array}{l}20 \mu \mathrm{l} / \mathrm{cm}^{2}, 3 \text { times a } \\
\text { week for } 4 \mathrm{wk}\end{array}$ & $\begin{array}{l}\text { Inflammatory cell infiltration } \downarrow \text {; expression of } \\
\text { iNOS and COX- } 2 \downarrow \text {; activity of NF- } \kappa \text { B and } \\
\text { release of TNF- } \alpha \text {, IL- } 1 \beta \text {, and IgE } \downarrow\end{array}$ & {$[41]$} \\
\hline $\begin{array}{l}\text { TECA and astaxanthin } \\
\text { combination ointment }\end{array}$ & $\begin{array}{l}\text { Phthalic anhydride-induced } \\
\text { AD model }\end{array}$ & $\begin{array}{l}20 \mu \mathrm{g} / \mathrm{cm}^{2}, 3 \text { times a } \\
\text { week for } 4 \mathrm{wk}\end{array}$ & $\begin{array}{l}\text { Phthalic anhydride-induced skin } \\
\text { morphological changes and ear thickness } \downarrow\end{array}$ & {$[42]$} \\
\hline $\begin{array}{l}\text { C. asiatica ethanol } \\
\text { extract }\end{array}$ & $\begin{array}{l}\text { 2,4-Dinitrochlorobenzene- } \\
\text { induced AD model }\end{array}$ & $\begin{array}{c}80 \mu \mathrm{g} / \mathrm{cm}^{2} \text { (topical) } \\
\text { or } 200 \mathrm{mg} / \mathrm{kg} / \mathrm{d} \\
(\text { oral }), 14 \mathrm{~d}\end{array}$ & $\begin{array}{c}\text { Mast cell infiltration } \downarrow \text {; expression of various } \\
\text { cytokines } \downarrow\end{array}$ & {$[43]$} \\
\hline
\end{tabular}

proinflammatory cytokines such as TNF- $\alpha$, IL-4, IL-5, IL-6, IL-10, and IL-17 [43].

2.4. Wounds. Skin wounds are characterized by injury to the skin due to trauma, tears, cuts, or contusions. Wound healing is a physiological process that restores skin integrity and repairs the damaged tissues. Skin wound healing proceeds in four phases: hemostasis, inflammation, proliferation, and remodeling [44].

Asiaticoside was found to promote normal human skin cell migration, attachment, and growth in an in vitro wound healing model. ECa 233, a standardized extract of C. asiatica, induced keratinocyte migration and promoted wound healing through the activation of FAK, Akt, and MAPK signaling pathways [45]. 
Table 4: Pharmaceutical effect of C. asiatica on skin wounds.

\begin{tabular}{|c|c|c|c|c|}
\hline \multicolumn{5}{|c|}{ In vitro } \\
\hline Material tested & Cell line/assay system & Maximum concentration & Effect & Reference \\
\hline $\begin{array}{l}\text { Standardized extract of } \\
\text { C. asiatica (ECa 233) }\end{array}$ & $\begin{array}{l}\text { Human keratinocyte cell } \\
\text { line }(\mathrm{HaCaT})\end{array}$ & $\begin{array}{l}100 \mu \mathrm{g} / \mathrm{ml} \\
\text { In vivo }\end{array}$ & Cell migration $\uparrow \underset{\uparrow}{\text { wound healing activity }}$ & {$[45]$} \\
\hline Material tested & Animal model & Dose, duration & Effect & Reference \\
\hline C. asiatica hydrogel & $\begin{array}{l}\text { New Zealand white albino } \\
\text { rabbits for an incision } \\
\text { model }\end{array}$ & $\begin{array}{l}\text { Appropriate amounts on } \\
\text { the area of incisional } \\
\text { wounds, } 12 \mathrm{~d}\end{array}$ & $\begin{array}{c}\text { Wound healing } \uparrow \text {; formation of a thick } \\
\text { epithelial layer, keratin, granulation } \\
\text { tissues, fibroblasts, and collagen } \uparrow\end{array}$ & {$[46]$} \\
\hline $\begin{array}{l}\text { Gelatin membranes } \\
\text { containing C. asiatica } \\
\text { methanol extract }\end{array}$ & $\begin{array}{l}\text { Male SD rats for an } \\
\text { incision model }\end{array}$ & $\begin{array}{l}\text { Covering the wound } \\
\text { surfaces, } 14 \mathrm{~d}\end{array}$ & $\begin{array}{c}\text { Wound healing } \uparrow \text {; collagen deposition } \\
\text { and angiogenesis } \uparrow\end{array}$ & {$[47]$} \\
\hline $\begin{array}{l}\text { Topical spray containing } \\
\text { C. asiatica methanol } \\
\text { extract }\end{array}$ & $\begin{array}{l}\text { Male Wistar rats for } \\
\text { excision wound model }\end{array}$ & $2.5 \mathrm{ml}$, once daily for $14 \mathrm{~d}$ & Wound healing $\uparrow$ & {$[48]$} \\
\hline $\begin{array}{l}\text { Asiaticoside nitric oxide } \\
\text { gel }\end{array}$ & $\begin{array}{l}\text { Male SD rats for an } \\
\text { incision model }\end{array}$ & $0.2 \mathrm{ml}$, twice daily for $14 \mathrm{~d}$ & $\begin{array}{c}\text { Healing rate of diabetic cutaneous ulcer } \\
\text { wounds } \uparrow \text {; growth of bacteria in the } \\
\text { wound surface } \downarrow\end{array}$ & {$[49]$} \\
\hline \multicolumn{5}{|c|}{ Clinical trial } \\
\hline Material tested & Study design/volunteer $(n)$ & Dose, duration & Effect & Reference \\
\hline $\begin{array}{l}\text { Standardized extract of } \\
\text { C. asiatica (ECa } 233 \text { gel) }\end{array}$ & $\begin{array}{l}\text { RCT, DB/patients with } \\
\text { bilateral atrophic facial } \\
\text { acne scars }(n=30)\end{array}$ & $\begin{array}{l}\text { Appropriate amount on } \\
\text { half-side of the face, twice } \\
\text { daily for } 3 \mathrm{mo}\end{array}$ & Post-laser-resurfacing wound healing $\uparrow$ & {$[50]$} \\
\hline
\end{tabular}

RCT: randomized controlled trial; DB: double blind.

Asiaticoside-rich hydrogel made from aerial parts of C. asiatica facilitated skin wound healing faster than the commercial cream and the untreated wounds in rabbits in an incision model [46]. The accelerated wound healing with $C$. asiatica hydrogel treatment may be owing to the formation of a thick epithelial layer, keratin, granulation tissues, fibroblasts, and collagen. The wound areas of rat skin treated with gelatin membranes containing $C$. asiatica methanol extract exhibited collagen deposition and a high number of capillaries, leading to enhanced skin wound healing [47].

In an in vivo excision wound model, there was significant wound healing in the animal group treated with topical spray containing $C$. asiatica methanol extract than in the untreated group [48]. Interestingly, asiaticoside nitric oxide gel promoted the healing rate of diabetic cutaneous ulcer wounds by regulating the $\mathrm{Wnt} / \beta$-catenin signaling pathway and inhibiting the growth of bacteria on the wound surface in a rat wound model with diabetic cutaneous ulcers [49].

In contrast to the abundant in vivo evidence of the woundhealing effect of $C$. asiatica, clinical studies are sparse. Yet, one clinical trial showed a significant improvement in post-laserresurfacing wound healing in patients with bilateral atrophic facial acne scars treated with ECa 233 gel for three months compared to the patients in the control group [50].

2.5. Other Skin Diseases. Vitiligo is a depigmenting skin disorder characterized by the selective loss of melanocytes which leads to pigment dilution in affected areas of the skin. It is the result of genetics and environmental causes in addition to metabolic stress, oxidative stress, and cell detachment abnormalities [51].
Madecassoside has attenuated mitochondrial damage caused by $\mathrm{H}_{2} \mathrm{O}_{2}$-induced oxidative stress in human epidermal melanocytes, suggesting that it could be a promising treatment for vitiligo mainly caused by oxidative stress (Table 5) [52].

Additionally, TECA promoted three-dimensional dermal papilla sphere formation by inhibiting the STAT activation in human dermal papilla cells, indicating TECA treatment may provide a useful strategy for promoting hair growth [53].

\section{Underlying Mechanisms for the Pharmacological Effects of Centella asiatica on Skin Diseases}

It has been reported that the feasible molecular mechanisms involved in the pharmacological effects of $C$. asiatica on skin diseases are as follows: NF- $\kappa \mathrm{B}$, TGF- $\beta /$ Smad, MAPK, Wnt/ $\beta$-catenin, and STAT signaling.

3.1. NF- $\kappa B$ Signaling. Nuclear factor-kappa B $(\mathrm{NF}-\kappa \mathrm{B})$ is a family of dimeric transcription factors that coordinate inflammatory responses, innate and adaptive immunity, and cellular differentiation, proliferation, and survival in almost all multicellular organisms [54]. The NF- $\kappa \mathrm{B}$ system is tightly regulated, and misregulation of $\mathrm{NF}-\kappa \mathrm{B}$ has been implicated in a wide range of diseases ranging from cancer to inflammatory and immune disorders. As a result, the NF- $\kappa \mathrm{B}$ regulatory network and its dynamics offer a multitude of promising therapeutic targets that remain to be fully explored and translated into clinical use [55]. 
TABLe 5: Pharmaceutical effects of C. asiatica on other skin diseases.

\begin{tabular}{lcccc}
\hline & & & & \\
& & & \\
Material tested & Cell line/assay system & Maximum concentration & Effect & Reference \\
\hline Madecassoside & Human epidermal melanocytes & $100 \mu \mathrm{g} / \mathrm{ml}$ & Damage of mitochondria $\downarrow$; oxidative stress $\downarrow$ & [52] \\
TECA & Human dermal papilla cells & $25 \mu \mathrm{g} / \mathrm{ml}$ & Potential of hair inductive capacity $\uparrow$ & [53] \\
\hline
\end{tabular}

Titrated extract of C. asiatica (TECA) treatment suppressed NF- $\kappa \mathrm{B}$ activity and subsequently inhibited the expression of TNF- $\alpha$, IL- $1 \beta$, and IL- 6 in a phthalic anhydride (PA)-induced atopic dermatitis (AD) animal model [40]. Furthermore, the addition of astaxanthin to TECA augmented the NF- $\kappa \mathrm{B}$-mediated anti-inflammatory activity of TECA [42]. Another similar report supports the therapeutic effect of $C$. asiatica on $\mathrm{AD}$ via $\mathrm{NF}-\kappa \mathrm{B}$ signaling. Topical treatment with $C$. asiatica phytosome inhibited the translocation of NF- $\kappa$ B into the nucleus and the release of TNF- $\alpha$, IL-1 $\beta$, and IgE, leading to the suppression of inflammatory cell infiltration [41]. In an in vitro assay, purified madecassoside, a major pentacyclic triterpene from C. asiatica, significantly inhibited the nuclear translocation of NF- $\kappa \mathrm{B}$ and IL- $1 \beta$ production as well as TLR2 expression in Propionibacterium acnes-stimulated THP-1 human monocytic cells [32].

3.2. TGF- $\beta /$ Smad Signaling. Transforming growth factor $-\beta$ (TGF- $\beta$ ) is considered a crucial mediator in tissue fibrosis and causes tissue scarring largely by activating its downstream small mothers against decapentaplegic (Smad) signaling [56]. TGF- $\beta$ plays a pivotal role in producing the myofibroblast phenotype, which is responsible for massive collagen deposition and contraction of wounds [57]. Since the TGF- $\beta$-induced Smad-dependent pathway is critical for the pathogenesis of all fibrotic diseases, various therapeutic strategies have been investigated to target the signaling pathway to attenuate aberrant skin scar formation [58].

Among the triterpenoid compounds of C. asiatica, the glycosides (asiaticoside and madecassoside) themselves, rather than their corresponding metabolites, asiatic acid and madecassic acid, are recognized as the main active constituents of $C$. asiatica herbs responsible for burn wound healing. Oral administration of both asiaticoside and madecassoside enhanced collagen type III synthesis by activating skin fibroblasts via the TGF- $\beta /$ Smad pathway and facilitated burn wound healing in male ICR mice [59].

3.3. MAPK Signaling. Mitogen-activated protein kinase (MAPK) is an important signaling pathway in living beings in response to extracellular stimuli. There are five main subgroups manipulated by a set of sequential actions: ERK (ERK1/ERK2), c-Jun N (JNK/SAPK), p38 MAPK ( $p 38 \alpha$, $p 38 \beta, p 38 \gamma$, and $p 38 \delta$ ), and ERK3/ERK4/ERK5 [60]. When stimulated, these groups have long been linked to multiple biological processes such as cell proliferation, differentiation, death, migration, invasion, and inflammation [61]. ECa 233, a standardized extract of C. asiatica, induced keratinocyte migration and subsequently promoted wound healing through the activation of FAK, Akt, and MAPK signaling pathways [45].

3.4. Wnt $/ \beta$-Catenin Signaling. The Wnt $/ \beta$-catenin pathway is one of the main processes in the regulation of a variety of biological processes including cell proliferation, apoptosis, and differentiation. It is also considered an important pathway in the healing of skin wounds. [62]. Asiaticoside nitric oxide gel promoted the healing rate of diabetic cutaneous ulcer wounds by regulating the $\mathrm{Wnt} / \beta$-catenin signaling pathway and inhibiting the growth of bacteria on the wound surface in a rat model with diabetic cutaneous ulcers [49].

3.5. STAT Signaling. The signal transducer and activator of transcription (STAT) signaling pathway is a universally expressed intracellular signal transduction pathway and is involved in many crucial biological processes, including cell proliferation, differentiation, apoptosis, and immune regulation [63]. Hair growth can be induced from resting mouse hair follicles by topical application of Janus kinase (JAK) inhibitors, suggesting that JAK/STAT signaling is required for maintaining hair follicle stem cells in a quiescent state [64]. The titrated extract of C. asiatica (TECA) promoted three-dimensional dermal papilla sphere formation by inhibiting STAT activation in human dermal papilla cells, indicating that TECA treatment may provide a useful strategy for promoting hair growth [53].

\section{Pharmacokinetic Properties of Active Compounds of Centella asiatica}

The complex composition of C. asiatica renders pharmacokinetic studies of its multiple active compounds in humans or animal models particularly challenging. To date, pharmacokinetic studies on the active compounds of C. asiatica have primarily focused on in vivo absorption, distribution, metabolism, and elimination (ADME), as well as the bioavailability of $C$. asiatica-specific triterpenoids asiaticoside, madecassoside, and their aglycones asiatic acid and madecassic acid.

One pharmacokinetic study on asiatic acid was conducted after oral administration of an encapsulated watersoluble extract obtained from the aerial parts of C. asiatica in beagle dogs [65]. The main pharmacokinetic parameters of asiatic acid obtained from beagle dog plasma were $T_{1 / 2}$, $4.29 \mathrm{~h} ; T_{\max }, 2.70 \mathrm{~h} ; C_{\max }, 0.74 \mu \mathrm{g} / \mathrm{ml} ; \mathrm{AUC}_{0-t}$ and $\mathrm{AUC}_{0-\infty}$, 3.74 and $3.82 \mu \mathrm{g} \mathrm{h} / \mathrm{ml}$. Another pharmacokinetic study suggested that the absolute oral bioavailability of asiatic acid in rats is very low (16.25\%), which may result from poor 
solubility and rapid metabolism [66]. Asiaticoside is converted in vivo to asiatic acid by hydrolytic cleavage of the sugar moiety, leading to little asiaticoside within the plasma after oral administration because of a proposed complete biotransformation into asiatic acid and its glucuronide and sulphate conjugates in a human study [67]. When pure madecassoside was administered orally as a single compound in rats, the pharmacokinetic parameters of madecassoside were $T_{\max }$ and $T_{1 / 2}$ of $0.90 \pm 0.14 \mathrm{~h}$ and $3.47 \pm 0.68 \mathrm{~h}$, respectively [68]. After a single oral dosing in rats, madecassoside was widely distributed in the heart, liver, spleen, lungs, and kidneys of rats and the levels of madecassoside in the liver and kidney were relatively higher than in other organs with primary elimination via the feces [69]. Notably, Anukunwithaya et al. conducted a disposition kinetic study on ECa 233, a standardized extract of C. asiatica, containing madecassoside (53.1\%) and asiaticoside (32.3\%) in rats [70]. Madecassoside and asiaticoside were rapidly absorbed, reaching maximum levels within 5-15 min after oral administration in rats, whereas madecassic and asiatic acids were found in negligible amounts. Both triterpenoid glycosides were extensively distributed in the brain, stomach, and skin within $1 \mathrm{~h}$ and remained there for at least $4 \mathrm{~h}$ after dosing. Interestingly, madecassoside and asiaticoside in ECa 233, administered orally at a dose of $100 \mathrm{mg} / \mathrm{kg}$, were rapidly distributed to the skin with an $\mathrm{AUC}_{(0-4)}$ of $667.22 \pm 121.06$ and $114.50 \pm 12.07 \mathrm{ng} \times \mathrm{h} / \mathrm{g}$ of skin tissue, respectively.

Few studies have examined the tissue distribution of triterpenes following oral administration or topical application, particularly the skin levels of these compounds. Although one study mentioned above [70] reported the dermal distribution of madecassoside and asiaticoside in a standardized extract of C. asiatica after oral dosing in rats, the cutaneous absorption rate of the active principles of topical application of C. asiatica has yet to be to be measured. Thus, further investigation is needed to understand the dermal distribution of these compounds and their metabolites.

\section{Conclusions and Perspectives}

Several in vitro and in vivo studies have demonstrated the therapeutic potential of Centella asiatica in the treatment of acne, burns, atopic dermatitis, and wounds. It has been suggested that the feasible molecular mechanisms involved in the pharmacological effects of $C$. asiatica on skin diseases include NF- $\kappa$ B, TGF- $\beta /$ Smad, MAPK, Wnt $/ \beta$-catenin, and STAT signaling. However, further intensive clinical trials are required to confirm its efficacy as a therapeutic agent for treating skin diseases.

Medicinal products containing C. asiatica preparations are authorized and marketed in some of the European countries including Belgium, France, Greece, Italy, Portugal, and Spain. For external use, cutaneous cream $1 \%$ and powder $2 \%$ are recommended to support the local treatment of moderate or benign problems in wound formation and to aid in the local treatment of cutaneous ulcerations. In addition, oral tablets containing the titrated extract of C. asiatica (TECA) are authorized as potent wound-healing agents [71]. Since various formulations of $C$. asiatica have already been authorized and marketed as wound-healing therapeutics such as Madecassol ${ }^{\circledR}$, Centellase ${ }^{\circledR}$, and Blastoestimulina ${ }^{\circledR}$, it could be considered that there is little need for clinical trials to confirm its effect on wound healing. However, extensive clinical studies are necessary to verify the healing effect of $C$. asiatica in subjects with various types and severities of wounds as well as the effect on skin diseases other than wounds, such as acne, burns, and atopic dermatitis.

\section{Data Availability}

The data used to support the findings of this study are available from the corresponding author upon request.

\section{Conflicts of Interest}

The author declares that there are no conflicts of interest regarding the publication of this paper.

\section{References}

[1] J. James and I. Dubery, "Pentacyclic triterpenoids from the medicinal herb, Centella asiatica (L.) urban," Molecules, vol. 14, no. 10, pp. 3922-3941, 2009.

[2] N. E. Gray, A. Alcazar Magana, P. Lak et al., "Centella asiatica-phytochemistry and mechanisms of neuroprotection and cognitive enhancement," Phytochemistry Reviews, vol. 17, no. 1, pp. 161-194, 2018.

[3] B. Brinkhaus, M. Lindner, D. Schuppan, and E. G. Hahn, "Chemical, pharmacological and clinical profile of the East Asian medical plant Centella asiatica," Phytomedicine, vol. 7, no. 5, pp. 427-428, 2000.

[4] O. A. Oyedeji and A. J. Afolayan, "Chemical composition and antibacterial activity of the essential oil of Centella asiatica. growing in South Africa," Pharmaceutical Biology, vol. 43, no. 3, pp. 249-252, 2005.

[5] E. N. Ncube, P. A. Steenkamp, N. E. Madala, and I. A. Dubery, "Chlorogenic acids biosynthesis in Centella asiatica cells is not stimulated by salicylic acid manipulation," Applied Biochemistry and Biotechnology, vol. 179, no. 5, pp. 685-696, 2016.

[6] B. Sun, L. Wu, Y. Wu et al., "Therapeutic potential of Centella asiatica and its triterpenes: a review," Frontiers in Pharmacology, vol. 11, Article ID 568032, 2020.

[7] J. Nataraj, T. Manivasagam, A. Justin Thenmozhi, and M. M. Essa, "Neurotrophic effect of asiatic acid, a triterpene of Centella asiatica against chronic 1-methyl 4-phenyl 1, 2, 3, 6tetrahydropyridine hydrochloride/probenecid mouse model of Parkinson's disease: the role of MAPK, PI3K-Akt-GSK3 $\beta$ and mTOR signalling pathways," Neurochemical Research, vol. 42, no. 5, pp. 1354-1365, 2017.

[8] D. Song, X. Jiang, Y. Liu, Y. Sun, S. Cao, and Z. Zhang, "Asiaticoside attenuates cell growth inhibition and apoptosis induced by $\mathrm{a} \beta_{1-42}$ via inhibiting the TLR4/NF- $\kappa \mathrm{B}$ signaling pathway in human brain microvascular endothelial cells," Frontiers in Pharmacology, vol. 9, Article ID 28, 2018.

[9] Maulidiani, F. Abas, A. Khatib, V. Perumal, V. Suppaiah et al., Metabolic alteration in obese diabetes rats upon treatment with Centella asiatica extract," Journal of Ethnopharmacology, vol. 180, pp. 60-69, 2016.

[10] B. Masola, O. O. Oguntibeju, and A. B. Oyenihi, "Centella asiatica ameliorates diabetes-induced stress in rat tissues via 
influences on antioxidants and inflammatory cytokines," Biomedicine and Pharmacotherapy, vol. 101, pp. 447-457, 2018.

[11] A. B. Oyenihi, S. O. P. Langa, S. Mukaratirwa, and B. Masola, "Effects of Centella asiatica on skeletal muscle structure and key enzymes of glucose and glycogen metabolism in type 2 diabetic rats," Biomedicine and Pharmacotherapy, vol. 112, Article ID 108715, 2019.

[12] P. Rameshreddy, V. V. S. Uddandrao, P. Brahmanaidu et al., "Obesity-alleviating potential of asiatic acid and its effects on ACC1, UCP2, and CPT1 mRNA expression in high fat dietinduced obese Sprague-Dawley rats," Molecular and Cellular Biochemistry, vol. 442, no. 1-2, pp. 143-154, 2018.

[13] X. Wang, X. Cai, W. Wang et al., "Effect of asiaticoside on endothelial cells in hypoxia-induced pulmonary hypertension," Molecular Medicine Reports, vol. 17, no. 2, pp. 28932900, 2018.

[14] P. Maneesai, S. Bunbupha, U. Kukongviriyapan et al., "Effect of asiatic acid on the Ang II-AT ${ }_{1} \mathrm{R}-\mathrm{NADPH}$ oxidase-NF- $\kappa \mathrm{B}$ pathway in renovascular hypertensive rats," NaunynSchmiedeberg's Archives of Pharmacology, vol. 390, no. 10, pp. 1073-1083, 2017.

[15] L. Jing, W. Haitao, W. Qiong, Z. Fu, Z. Nan, and Z. Xuezheng, "Anti-inflammatory effect of asiaticoside on human umbilical vein endothelial cells induced by ox-LDL," Cytotechnology, vol. 70, no. 2, pp. 855-864, 2018.

[16] L. Y. Fong, C. T. Ng, Y. K. Yong, M. N. Hakim, and Z. Ahmad, "Asiatic acid stabilizes cytoskeletal proteins and prevents TNF- $\alpha$-induced disorganization of cell-cell junctions in human aortic endothelial cells," Vascular Pharmacology, vol. 117, pp. 15-26, 2019.

[17] M. J. Choi, H. M. Zheng, J. M. Kim, K. W. Lee, Y. H. Park, and D. H. Lee, "Protective effects of Centella asiatica leaf extract on dimethylnitrosamine-induced liver injury in rats," Molecular Medicine Reports, vol. 14, no. 5, pp. 4521-4528, 2016.

[18] W. Wang, L. Wu, Q. Li et al., "Madecassoside prevents acute liver failure in LPS/D-GalN-induced mice by inhibiting $p 38$ / $\mathrm{NF}-\kappa \mathrm{B}$ and activating Nrf2/HO-1 signaling," Biomedicine and Pharmacotherapy, vol. 103, pp. 1137-1145, 2018.

[19] L. Wei, Q. Chen, A. Guo, J. Fan, R. Wang, and H. Zhang, "Asiatic acid attenuates $\mathrm{CCl}_{4}$-induced liver fibrosis in rats by regulating the PI3K/AKT/mTOR and Bcl-2/Bax signaling pathways," International Immunopharmacology, vol. 60, pp. 1-8, 2018.

[20] T. Intararuchikul, N. Teerapattarakan, R. Rodsiri et al., "Effects of Centella asiatica extract on antioxidant status and liver metabolome of rotenone-treated rats using GC-MS," Biomedical Chromatography, vol. 33, no. 2, p. e4395, 2019.

[21] H. M. Zheng, M. J. Choi, J. M. Kim et al., "Centella asiatica leaf extract protects against indomethacin-induced gastric mucosal injury in rats," Journal of Medicinal Food, vol. 19, no. 1, pp. 38-46, 2016.

[22] X. Xu, Y. Wang, Z. Wei et al., "Madecassic acid, the contributor to the anti-colitis effect of madecassoside, enhances the shift of Th17 toward treg cells via the PPAR $\gamma / A M P K /$ ACC1 pathway," Cell Death and Disease, vol. 8, no. 3, p. e2723, 2017.

[23] S. H. Dong, Y. W. Liu, F. Wei, H. Z. Tan, and Z. D. Han, "Asiatic acid ameliorates pulmonary fibrosis induced by bleomycin (BLM) via suppressing pro-fibrotic and inflammatory signaling pathways," Biomedicine and Pharmacotherapy, vol. 89, pp. 1297-1309, 2017.

[24] J. W. Lee, H. A. Park, O. K. Kwon et al., "Asiatic acid inhibits pulmonary inflammation induced by cigarette smoke," International Immunopharmacology, vol. 39, pp. 208-217, 2016.
[25] J. Qiu, L. Yu, X. Zhang et al., "Asiaticoside attenuates lipopolysaccharide-induced acute lung injury via down-regulation of NF- $\kappa \mathrm{B}$ signaling pathway," International Immunopharmacology, vol. 26, no. 1, pp. 181-187, 2015.

[26] W. Bylka, P. Znajdek-Awiżeń, E. Studzińska-Sroka, A. Dańczak-Pazdrowska, and M. Brzezińska, "Centella asiatica in dermatology: an overview," Phytotherapy Research, vol. 28, no. 8, pp. 1117-1124, 2014.

[27] C. Dessinioti and A. D. Katsambas, "The role of propionibacterium acnes in acne pathogenesis: facts and controversies," Clinics in Dermatology, vol. 28, no. 1, pp. 2-7, 2010.

[28] H. Gollnick, "Current concepts of the pathogenesis of acne: implications for drug treatment," Drugs, vol. 63, no. 15, pp. 1579-1596, 2003.

[29] L. Fox, C. Csongradi, M. Aucamp, J. du Plessis, and M. Gerber, "Treatment modalities for acne," Molecules, vol. 21, no. 8, p. 1063, 2016.

[30] C. W. Kuo, Y. F. Chiu, M. H. Wu et al., "Gelatin/chitosan bilayer patches loaded with cortex Phellodendron amurense/ Centella asiatica extracts for anti-acne application," Polymers, vol. 13, no. 4, p. 579, 2021.

[31] C. Jantarat, P. Sirathanarun, T. Chuchue, A. Konpian, G. Sukkua, and P. Wongprasert, "In vitro antimicrobial activity of gel containing the herbal ball extract against Propionibacterium acnes," Scientia Pharmaceutica, vol. 86, no. 1, p. 8, 2018.

[32] X. Shen, M. Guo, H. Yu, D. Liu, Z. Lu, and Y. Lu, "Propionibacterium acnes related anti-inflammation and skin hydration activities of madecassoside, a pentacyclic triterpene saponin from Centella asiatica," Bioscience, Biotechnology, and Biochemistry, vol. 83, no. 3, pp. 561-568, 2019.

[33] M. G. Jeschke, M. E. van Baar, M. A. Choudhry, K. K. Chung, N. S. Gibran, and S. Logsetty, "Burn injury," Nature Reviews, Disease Primers, vol. 6, no. 1, p. 11, 2020.

[34] M. P. Rowan, L. C. Cancio, E. A. Elste et al., "Burn wound healing and treatment: review and advancements," Critical Care, vol. 19, p. 243, 2015.

[35] Q. Hou, M. Li, Y. H. Lu, D. H. Liu, and C. C. Li, "Burn wound healing properties of asiaticoside and madecassoside," Experimental and Therapeutic Medicine, vol. 12, no. 3, pp. 1269-1274, 2016.

[36] S. Bardaa, D. Moalla, S. Ben Khedir, T. Rebai, and Z. Sahnoun, "The evaluation of the healing proprieties of pumpkin and linseed oils on deep second-degree burns in rats," Pharmaceutical Biology, vol. 54, no. 4, pp. 581-587, 2016.

[37] A. Saeidinia, F. Keihanian, A. P. Lashkari et al., "Partialthickness burn wound healing by topical treatment: a randomized controlled comparison between silver sulfadiazine and centiderm," Medicine, vol. 96, no. 9, p. 103, 2017.

[38] P. Muangman, B. Praditsuktavorn, K. Chinaroonchai, and C. Chuntrasakul, "Clinical efficacy test of polyester containing herbal extract dressings in burn wound healing," The International Journal of Lower Extremity Wounds, vol. 15, no. 3, pp. 203-212, 2016.

[39] W. David Boothe, J. A. Tarbox, and M. B. Tarbox, "Atopic dermatitis: pathophysiology," Advances in Experimental Medicine and Biology, vol. 1027, pp. 21-37, 2017.

[40] J. H. Park, J. Y. Choi, D. J. Son et al., "Anti-inflammatory effect of titrated extract of Centella asiatica in phthalic anhydrideinduced allergic dermatitis animal model," International Journal of Molecular Sciences, vol. 18, no. 4, p. 738, 2017.

[41] J. H. Park, J. S. Jang, K. C. Kim, and J. T. Hong, "Anti-inflammatory effect of Centella asiatica phytosome in a mouse model of phthalic anhydride-induced atopic dermatitis," Phytomedicine, vol. 43, pp. 110-119, 2018. 
[42] J. H. Park, I. J. Yeo, J. S. Jang et al., "Combination effect of titrated extract of Centella asiatica and astaxanthin in a mouse model of phthalic anhydride-induced atopic dermatitis," Allergy, Asthma and Immunology Research, vol. 11, no. 4, pp. 548-559, 2019.

[43] Y. Lee, H. K. Choi, K. P. U. N'deh et al., "Inhibitory effect of Centella asiatica extract on DNCB-induced atopic dermatitis in $\mathrm{HaCaT}$ cells and BALB/c mice," Nutrients, vol. 12, no. 2, p. 411, 2020.

[44] N. Pazyar, R. Yaghoobi, E. Rafiee, A. Mehrabian, and A. Feily, "Skin wound healing and phytomedicine: a review," Skin Pharmacology and Physiology, vol. 27, no. 6, pp. 303-310, 2014.

[45] S. Singkhorn, M. H. Tantisira, S. Tanasawet, P. Hutamekalin, T. Wongtawatchai, and W. Sukketsiri, "Induction of keratinocyte migration by ECa 233 is mediated through FAK/Akt, ERK, and p38 MAPK signaling," Phytotherapy Research, vol. 32, no. 7, pp. 1397-1403, 2018.

[46] A. Sh Ahmed, M. Taher, U. K. Mandal et al., "Pharmacological properties of Centella asiatica hydrogel in accelerating wound healing in rabbits," BMC Complementary and Alternative Medicine, vol. 19, no. 1, p. 213, 2019.

[47] C. H. Yao, J. Y. Yeh, Y. S. Chen, M. H. Li, and C. H. Huang, "Wound-healing effect of electrospun gelatin nanofibres containing Centella asiatica extract in a rat model," Journal of Tissue Engineering and Regenerative Medicine, vol. 11, no. 3, pp. 905-915, 2017.

[48] S. Sawatdee, K. Choochuay, W. Chanthorn, and T. Srichana, "Evaluation of the topical spray containing Centella asiatica extract and its efficacy on excision wounds in rats," Acta Pharmaceutica, vol. 66, no. 2, pp. 233-244, 2016.

[49] X. Nie, H. Zhang, X. Shi et al., "Asiaticoside nitric oxide gel accelerates diabetic cutaneous ulcers healing by activating $\mathrm{Wnt} / \beta$-catenin signaling pathway," International Immunopharmacology, vol. 79, Article ID 106109, 2020.

[50] W. Damkerngsuntorn, P. Rerknimitr, R. Panchaprateep et al., "The effects of a standardized extract of Centella asiatica on postlaser resurfacing wound healing on the face: a split-face, double-blind, randomized, placebo-controlled trial," Journal of Alternative and Complementary Medicine, vol. 26, no. 6, pp. 529-536, 2020.

[51] M. Picardo, M. L. Dell'Anna, K. Ezzedine et al., "Vitiligo," Nature Reviews, Disease Primers, vol. 1, p. 15011, 2015.

[52] Y. Ling, Q. Gong, X. Xiong et al., "Protective effect of madecassoside on $\mathrm{H}_{2} \mathrm{O}_{2}$-induced oxidative stress and autophagy activation in human melanocytes," Oncotarget, vol. 8, no. 31, pp. 51066-51075, 2017.

[53] Y. M. Choi, S. An, J. Lee et al., "Titrated extract of Centella asiatica increases hair inductive property through inhibition of STAT signaling pathway in three-dimensional spheroid cultured human dermal papilla cells," Bioscience, Biotechnology, and Biochemistry, vol. 81, no. 12, pp. 2323-2329, 2017.

[54] S. Mitchell, J. Vargas, and A. Hoffmann, "Signaling via the $\mathrm{NF}-\kappa \mathrm{B}$ system," Wiley Interdisciplinary Reviews. Systems Biology and Medicine, vol. 8, no. 3, pp. 227-241, 2016.

[55] J. D. Kearns and A. Hoffmann, "Integrating computational and biochemical studies to explore mechanisms in NF- $\kappa \mathrm{B}$ signaling," Journal of Biological Chemistry, vol. 284, no. 9, pp. 5439-5443, 2009.

[56] H. H. Hu, D. Q. Chen, Y. N. Wang et al., "New insights into TGF- $\beta$ /Smad signaling in tissue fibrosis," Chemico-Biological Interactions, vol. 292, pp. 76-83, 2018.

[57] J. M. Carthy, "TGF- $\beta$ signaling and the control of myofibroblast differentiation: implications for chronic inflammatory disorders," Journal of Cellular Physiology, vol. 233, no. 1, pp. 98-106, 2018.

[58] T. Zhang, X. F. Wang, Z. C. Wang et al., "Current potential therapeutic strategies targeting the TGF- $\beta /$ Smad signaling pathway to attenuate keloid and hypertrophic scar formation," Biomedicine and Pharmacotherapy, vol. 129, Article ID 110287, 2020.

[59] F. Wu, D. Bian, Y. Xia et al., "Identification of major active ingredients responsible for burn wound healing of Centella asiatica herbs," Evidence-Based Complementary and Alternative Medicine, vol. 2012, Article ID 848093, 13 pages, 2012.

[60] J. Whyte, O. Bergin, A. Bianchi, S. McNally, and F. Martin, "Key signalling nodes in mammary gland development and cancer. Mitogen-activated protein kinase signalling in experimental models of breast cancer progression and in mammary gland development," Breast Cancer Research, vol. 11, no. 5, p. 209, 2009.

[61] Y. Y. Lei, W. J. Wang, J. H. Mei, and C. L. Wang, "Mitogenactivated protein kinase signal transduction in solid tumors," Asian Pacific Journal of Cancer Prevention, vol. 15, no. 20, pp. 8539-8548, 2014.

[62] H. Zhang, X. Nie, X. Shi et al., "Regulatory mechanisms of the wnt/ $\beta$-catenin pathway in diabetic cutaneous ulcers," Frontiers in Pharmacology, vol. 9, p. 1114, 2018.

[63] P. Xin, X. Xu, C. Deng et al., "The role of JAK/STAT signaling pathway and its inhibitors in diseases," International Immunopharmacology, vol. 80, Article ID 106210, 2020.

[64] E. C. E. Wang, Z. Dai, A. W. Ferrante, C. G. Drake, and A. M. Christiano, "A subset of TREM2 ${ }^{+}$dermal macrophages secretes oncostatin $M$ to maintain hair follicle stem cell quiescence and inhibit hair growth," Cell Stem Cell, vol. 24, no. 4, pp. 654-669, 2019.

[65] X. C. Zheng and S. H. Wang, "Determination of asiatic acid in beagle dog plasma after oral administration of Centella asiatica extract by precolumn derivatization RP-HPLC," Journal of Chromatography B, vol. 877, pp. 477-481, 2009.

[66] Y. Yuan, H. Zhang, F. Sun, S. Sun, Z. Zhu, and Y. Chai, "Biopharmaceutical and pharmacokinetic characterization of asiatic acid in Centella asiatica as determined by a sensitive and robust HPLC-MS method," Journal of Ethnopharmacology, vol. 163, pp. 31-38, 2015.

[67] W. R. Rush, G. R. Murray, and D. J. M. Graham, "The comparative steady-state bioavailability of the active ingredients of madecassol," European Journal of Drug Metabolism and Pharmacokinetics, vol. 18, pp. 323-326, 1993.

[68] W. J. Han, Y. F. Xia, and Y. Dai, "Development and validation of high-performance liquid chromatography/electrospray ionization mass spectrometry for assay of madecassoside in rat plasma and its application to pharmacokinetic study," Biomedical Chromatography, vol. 26, pp. 26-32, 2012.

[69] D. D. Leng, W. J. Han, Y. Rui, Y. Dai, and Y. F. Xia, “In vivo disposition and metabolism of madecassoside, a major bioactive constituent in Centella asiatica (L.) Urb," Journal of Ethnopharmacology, vol. 150, pp. 601-608, 2013.

[70] T. Anukunwithaya, M. H. Tantisira, B. Tantisira, and P. Khemawoot, "Pharmacokinetics of a standardized extract of Centella asiatica ECa 233 in rats," Planta Medica, vol. 83, no. 8, pp. 710-717, 2017.

[71] European Medicines Agency, Assessment Report on Centella asiatica (L.) Urban, Herba, European Medicines Agency, Amsterdam, Netherlands, 2012. 